In this haphazard way of using digitalis the heart is never held in good control. In exceptional cases, where there is urgent need to push the drug, digitalin is best used subcutaneously. In ordinary cases a dose of 10 minims of the tincture every four, or 15 minims every eight, hours, or 5 minims every waking hour, is sufficient. Thus given, the patient being at rest, it generally takes about three days before the pulse is under control, and the urine begins to increase. When its decided effects are thus gradually developed the drug should be steadily continued in doses calculated to maintain its effect. With ordinary watchfulness there is no risk whatever; timely warning of excess is given by the pulse, which having become slow begins to exhibit small intermediate beats, and especially a tendency to go in couples. This is always a sign to reduce the doses or to omit for a few hours. The sickness that occasionally-too oftensupervenes with digitalis, is most troublesome. An occasional mercurial will sometimes prevent it, a change to digitalin in equivalent doses may be tried, or a tumbler of very hot water taken occasionally. In some cases it is not to be overcome except by omitting the drug; the patient is usually well under the influence of the drug before this symptom appears, in which case a small dose of digitalin by the mouth or hypodermically may be sutficient to maintain its effect on the heart.

In speaking of digitalis, I have regarded that drag as representing the whole therapeutic group. Digitalis is, to my mind, so far in front of all the others in efficacy, that in critica cases I should never think of prescribing any other member of the group before it. Strophanthus comes next to it in usefulness, and in physiological experiment is even more powerful. Clinically one is not so well satisfied with it, and this may possibly be prejudiced, bat I have had doubts about its stability in prescriptions. It causes the same troublesome nausea. The one reason for its use is that it affects the small vessels less; this gives it an advantage in some cases, particularly, perhaps, in carrying on the effects of digitalis in convalescent aortic regurgitant and mitral stenosis cases. But as I have endeavoured to point out, under most conditions calling for its use this very action upon the arterioles is one of the valuable attributes of digitalis, and explains, possibly, its superiority over strophanthus. I frequently, however, combine the two drugs when I want to secure an increased cardiac effect without using digitalis in doses large enough to contract the vessels too much. Convallaria comes next as a cardiac tonic in mild cases. I have only very occasionally used sparteine. One may observe that the earliest sign of amendment in cardiac failure is an increased flow of urine. A somewhat analogous relief of the stress of symptoms wil often be observed with the commencement of dropsical effusion, provided that effusion, of course, be limited to the cellular and peritoneum tissue. The peculiar restlessness and discomfort that precede the onset of dropsy are sometimes very remarkable, and the dropsical effusion should rightly be regarded as one of those compromises of Nature which enable the vital machinery to go on a little longer. Dropsy is due primarily to a leakage from the congested capillaries into the cellular tissue. It is also due to a retarded removal of the fluids by the lymphatic vessels.

From a therapeutic point of view the osmotic circulation in the cellular tissue and serous and mucous cavities is scarcely less important than the vessel circulation discovered by Harvey. The interchange between the two circulations amounts normally to many pints in the twenty-four hours, and cellular tissue and lymphatic vessels conduct a considerable share of it. The current of lymph is of extremely low pressure, and a very slight backward pressure in the veins will embarrass it. In dropsy not only is there venous retardation in the capillaries encouraging excessive exudation, but the retarded current in the great veins is a further obstruction to removal by the lymphatic vessels. Hence a consider able collection of fluid, even many pints, may be removed from circulation. The immediate effect of this removal is often a very decided relief to the patient's distress. The occurrence of dropsy may thus sometimes afford time for the readjustment of the circulatory balance in the heart and vessels. But if with the help of remedies this does not take place and the dropsy advances the question comes, when to interfere? The answer is: Not until it is estimated that the pressure in the collular tissue becomes great enough to equal or exceed the pressure in the capillaries. At this point interference becomes imperative, and the fluid should be removed by the employment of Southey's tubes, incisions, or simple punctures.

Very striking instances of long-abiding relief are met with from time to time from this treatment. I may quote a very remarkable case in this connection, illustrating a point which I have observed, namely, that dropsy occurs in some cases in the absence of heart phenomena which would appear sufficient to produce it :

A lady, aged about 50 , had been under my observation for some years for most intense chronic asthma, with emphysema and recurrent attacks of bronchitis. Her condition at many times seemed almost hopeless, but the one redeeming feature about her was the heart's action, which remained steady and well-sustained through her worst attacks; although there was undoubtedly some dilatation and hypertrophy of the right side of the the heart, there was no sign of heart failure. Towards the end of a bad summer in 1896 her legs began to swell, and as her distress increased with the cold weather they flled up, and by December the thighs and abdominal walls were greatly distended. She was in othor respects so ill at this time that I hesitated to tap the legs until they became too prominent a factor in her distress. Even now, although the heart's action murnurs. She was placed in a chair, and by means of four Southey's tubes 20 pints of Aluid were withdrawn in the course of fifty-two hours. Now, it is remarkable that there has never been any return of the dropsy, although she has not been free from bronchitic attacks: the limbs are perfeculy slim and natural, without a trace of edema. The heart's action perfectl slim maintained as before, It only partially failed for a few days

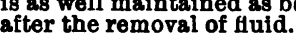

I may say that this lady has never been able to take digitalis nor any drug of that series with advantage, and it has never been prescribed for her except for short times at rare intervals, and in very small doses. I should regard the retarded venous return from the great emphysema obstructing the lungs, in combination with an over-burdened right heart as responsible for the dropsy, but the case is one of a few I have seen of the kind, difficult satisfactorily to explain. It is possible that it may be an unusually prominent example of the effect of a mechanism that has more to do with dropsy than has been generally allowed, namely, obstructed venous return in the chest from great emphysema aud dilated right heart, telling upon the lymphatic current in such a manner as to lessen the readiness of its escape into the innominate vein and so to hold in abeyance the share taken by lymphatic absorption in the removal of dropsical fluids.

1 Collected Works, vol. iv, p. 347. 2 Ibid., vol. 'iv, p. 384. 3 Quoted with acceptance by Lauder Brunton, Journal of Physiology, vol. Xx, 1896, p. 357 .

THE HUNTERIAN LECTURES oN TIIB

SURGERY OF. THE KIDNEY. Delivered at the Royal College of Surgeons of England, BY HENRY MORRIS, F.R.C.S., gurgeon to the Middlesex Hospital.

LECTURE I.

(Continued from page 815.)

Operations on the Ureters (Continued).

Resection of the ureter is the operation whereby an inch or two, or a little more, of the duct is removed, and the ureter is united to the infundibulum, or the divided ends of the ureter to one another, as the case may be, so as to restore the continuity of the conduit.

It was first proposed by Marcel Baudoin in 1891, and first performed by Küster in May, 1891. Küster's case is a most important one, not only as being the pioneer case, but as a serious warning that we ought to practise conservatism in dealing with the kidney; and an indication that in hydronephrosis nephrectomy ought to give place to nephrotomy, or to ureterotomy, in any case in .which either of these operations gives promise of success.

Küster reported his case at the Congress of Surgeons held in Berlin in 1892.15 The patient was a boy, aged 13, with only a single kidney, who for two years had passed all his urine through a fistula, following lumbar nephrotomy, for hydronephrosis. The cause of the hydronephrosis was very tight stricture near the renal pelvis. The strictured 
part of the ureter was excised, and the cat end of the nreter was sutured to the renal pelvis. By the end of four months from the date of this operation all the urine was nassed naturally, and the fistula was quite closed.

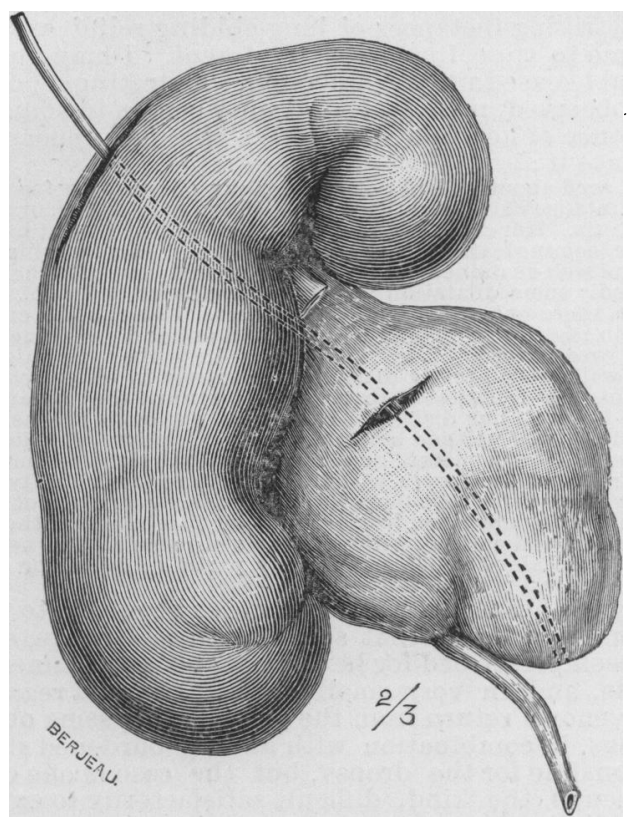

Fig. 6.-Abnormal relation of ureter to infundibulum before operation (author's case)

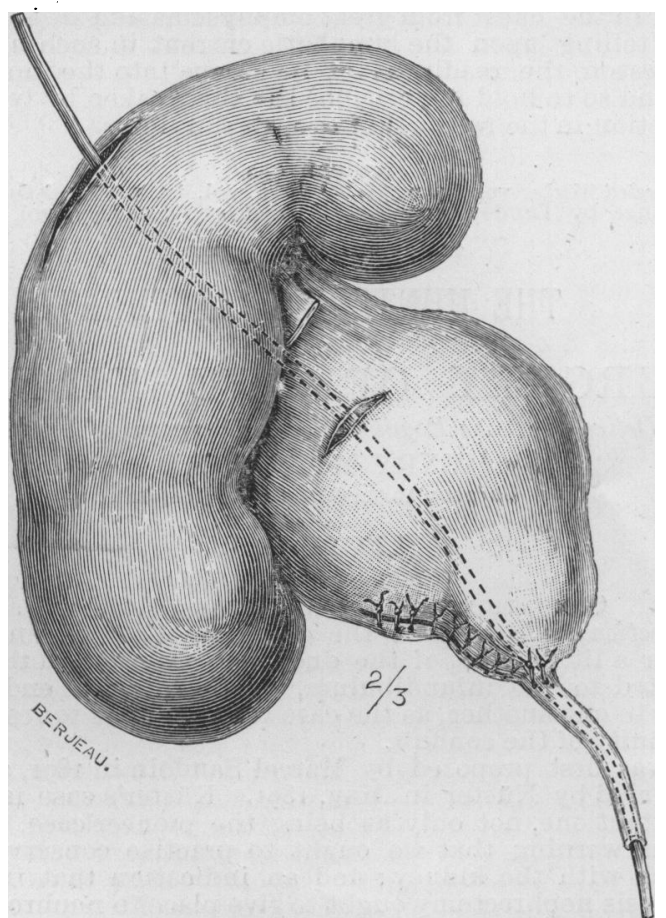

Fig. 7.-Relation ( $f$ treter to infundibul $\mathrm{am}$ after resection (author's case).

In the discussion on Küster's communication at the Berlin Congress Trendelenburg and Alsberg reported that they had each done a similar operation. Trendelenburg added that his patient had died from intestinal obstruction, due to adhesions between the hydronephrotic sac and the colon.

Cramer, of Cologne, follcwed Küster's lead in a case of hydronephrosis in 1893 , and again in operating on a case of pyonephrosis in 1894 ; in both a non-urinary short fistula was present when the patients were last seen. ${ }^{16}$

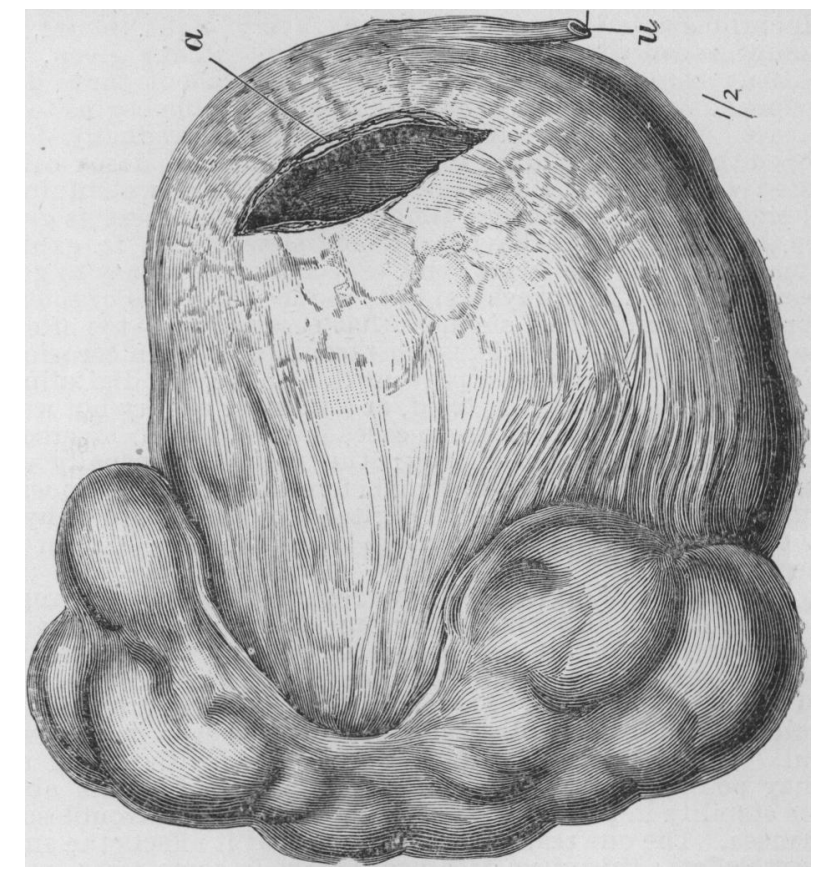

Fig. 8. - Kidney with enlarged pelvis containing plates of lime. It shows an abnormal relation of the renal pelvis to the ureter, Which might at an earlier period have been remedied by operation (uretero-pyelo-neostomy), and the hydronephrosis thus pre-
vented (Middlesex Hospital, October 30 th, r895). In author's list of nephrectomies.

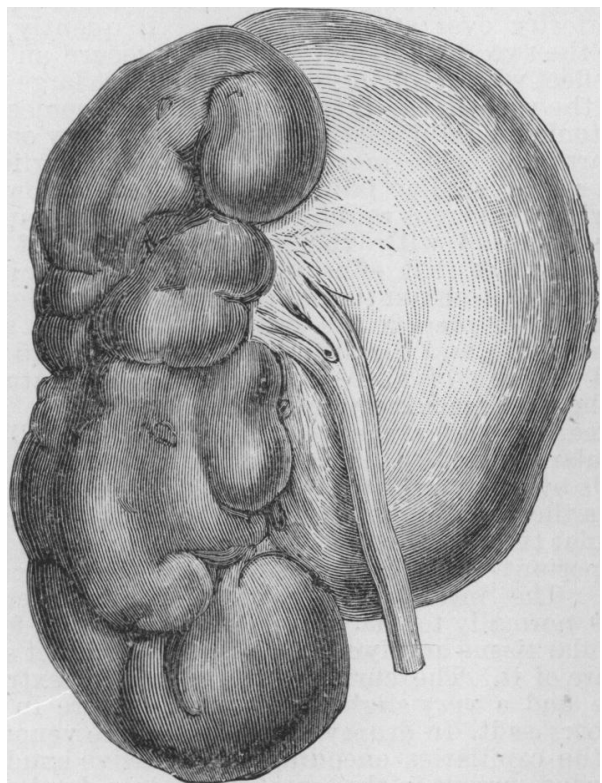

Fig. 9.-The same abnormality, but to an even greater=degree, is shown in this specimen. The hydronephrosis might have been prevented by a plastic operation (uretero-pyelo-neostomy). In author's list of nephrestomies.

Enderlen, in a paper on the Surgery of the Ureter, ${ }^{17}$ relates a case in the practice of Helferich, in which Küster's operation was performed upon a young woman of 25 , with hydronephrosis. She died on the ninth day with symptoms of anuria. At the necropsy the kidney of the opposite side was also hydronephrotic from an obliterated ureter.! [Nephrec- 
tomy in this case would have been even more rapidly fatal. As stenosis seems to have followed the plastic operation in this instance, one is led to ask why a lumbar renal fistula was not established as soon as the signs of anuria set in.

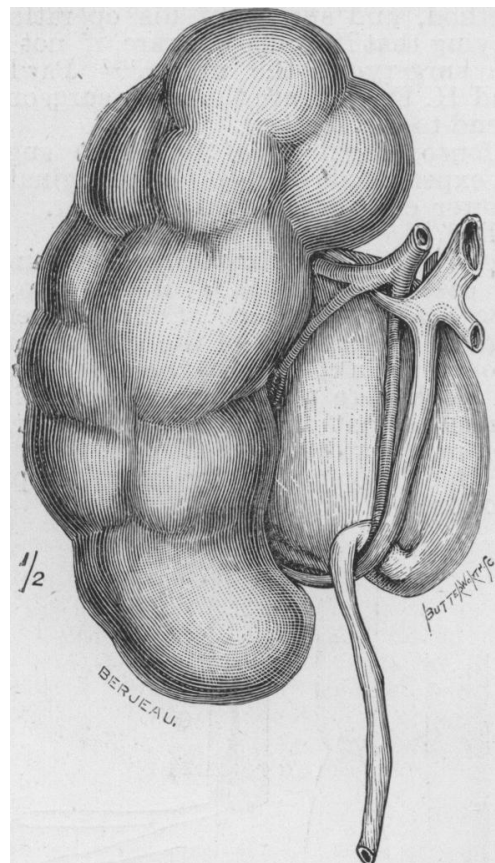

Wig. ro.-Hydronephrosis. Treter compressed by renal vessel (Guy's, No. 1694 in catalogue). Abnormality remediable by uretero-pyeloneostomy).

M. Bazy ${ }^{18}$ in October, 1896 , performed a precisely similar operation, to which he gave the name of uretéro-pyelo-néostomie. His patient was a man, aged 40, with a large hydronephrosis, for which relief was given by evacuating the pent-up urine by laparotomy. This gave $M$. Bazy the opportunity of ascertaining that the hydronephrotic kidney was of very fair secreting capacity.

The cause of the distension was the abnormality of the connection of the ureter with the renal pelvis; it opened into the infundibulum above its equator instead of at its lowest part. The incision into the hydronephrotic pouch was prolonged downwards and backwards; 4 centimetres of the ureter were cut away; the cut end of the ureter was split dongitudinally to the length of a centimetre and a-half, so as to enlarge the orifice of communication, and was then fixed to the back of the dilated infundibulum at its most dependent part. On the seventh day after the operation the urine was passed from the kidney operated upon to the bladder. One month later the abdominal wound was completely healed. At the end of five months the patient reported himself as being in excellent health.

Weller Van Hook ${ }^{19}$ in 1893 published a case in which he practised Küster's operation, but immediately he had completed it he found an obstruction in the ureter lower down, and therefore removed the kidney.

In 1897 I operated upon a female patient, aged 56 , for painful intermittent hydronephrosis, and found the ureter running obliquely in the wall of the distended renal pelvis. In this case I first laid the ureter and renal pelvis freely open into one another, and stitched the divided edges of the areter to those of the renal pelvis. The result was not satisfactory, so I excised an inch or more of the wreter, closed the greater part of the incision in the renal pelvis, and then sutured the ureter to the lowest part of the infundibulum as Küster had done (Figs. 6 and 7). Again the result did not satisfy me because of the small calibre and extreme tenuity of the ureter; so, to avoid a fistula and a long convalescence on the one hand, or stenosis of the areter at the site of operation and a subsequent nephrectomy on the other hand,
I removed the kidney there and then. Had the patient been younger or more robust I should, even with so small a ureter, have given the pl ustic operation a chance. The case, however, testifies to the feasibility of both Fenger's and Küster's operations.

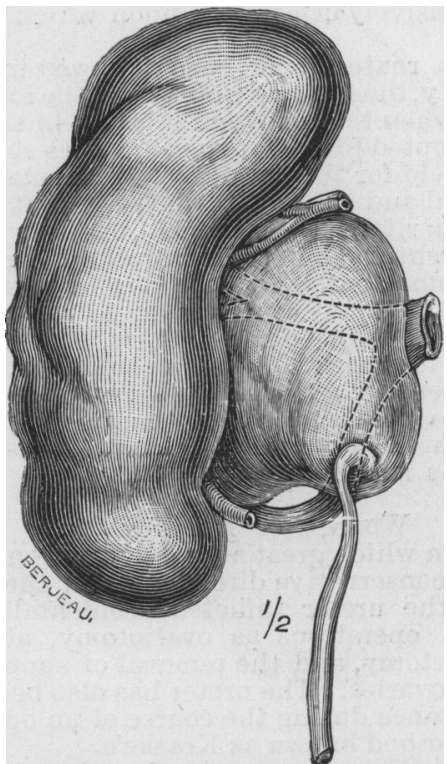

Fig. Ir.-Hydronephrosis. Ureter kinked on renal pelvis; described as kinked over ronal vein (Gur's No ing in catalogue) Abnormality remediable by uretero-pyelo-neostomy.

The 9 operations for resection of the ureter for hydronephrosis (or pyonephrosis) above quoted show that the aim in our treatment of hydronephrosis ought to be conservative. Before actually proceeding to resect the ureter for stricture or a valve, the surgeon should not fail to ascertain whether there is a clear channel in the areter below the stricture or valve to be divided, otherwise he may find that the operation is useless when completed, as it was in Van Hook's case. In some cases it may happen, even if the rest of the ureter is unobstructed and the plastic operation has been completed, that the small calibre or extreme tenuity of the walls of the ureter may make the operator dissatisfied with the result, In view of probable future stenosis. Under these circumstances nephrectomy will be required after all. But the attempt ought to be made, in every instance where the conditions are not actually unfavourable, to preserve the kidney by means of a plastic operation.

Ureterectomy. - By resection of the ureter is meant, as stated above, the cutting out of a short piece of the duct, not exceeding 2 to $2 \frac{1}{2}$ ins., with the object of restoring it to its proper capacity as a conduit of the urine to the bladder. It is a truly conservative operation. More extensive excisions of the ureter, and even the removal of the whole length of the duct, have of late years been occasionally practised, and with most beneficial results; but, like nephrectomy, such operations are, of course, not of a conservative nature.

Ureterectomy, partial or complete, has been performed for tuberculosis, suppuration in the dilated ureter, hydrops of the ureter, and for the cure of suppurating lumbar fistula due to the presence of a diseased ureter, after nephrectomy had been done. The operation has been either primary or secondary. It is primary when the ureter is removed simultaneously with the kidney, secondary when the excision of the ureter follows the removal of the kidney of the same side as a distinct subsequent operation.

Secondary total ureterectomy was first performed piecemeal by Regnier in 1892, and since by Gerster, of New York, in 1896 and by myself in $1896^{20}$; secondary partial ureterectomy by Poncet in 1894, by myself in March, 1896 .

Primary total ureterectomy was performed by Kelly, of Baltimore, in 1896, and by McCosh in 1896, and by myself in September, 1897. In my case there had been a partial 
excision of the kidney previously, but the greater part of the organ was removed at the same time as the ureter.

Primary partial ureterectomy was performed first by Tuffier in 1891, then by Postnikow in 1892, by Kelly and myself in 1893; and I have recently published a case in which the ureter was extensively calcareous, upon which I operated in August, 1895.21

Two different routes have been followed in the complete removal-namely, the transperitoneal and the extraperitoneal; but the latter, when the incision indicated in the accompanying figure is adopted [diagram shown], gives so complete and satisfactory a field for the necessary manipulations, and has other anatomical and surgical advantages, that it is not probable the transperitoneal method will find any followers.

Several different routes have been taken or suggested for partial ureterectomy affecting the lower part of the duct. In the male the inguinal extraperitoneal route (see Lecture III for description of incision)-that is, through an incision the same as the lower part of the incision for complete extraperitoneal ureterectomy, is the best; but in the female, the parasacral, or a combination of the inguinal and vaginal methods as practised by Kelly, has advantages over the others [diagrams shown].

\section{WOUNDS OF THE URETER.}

Another way in which great advance has been made in renal surgery, in the conservative direction, is in the management of wounds of the ureter inflicted accidentally during the course of such operations as ovariotomy, abdominal and vaginal hysterectomy, and the removal of suppurating Fallopian tubes and ovaries. The ureter has also been wounded in at least one instance during the course of an operation on the pelvis by the method known as Kraske's.

Spencer Wells, ${ }^{22}$ in his, paper on the first successful removal of a gravid cancerous uterus, stated that out of 94 published abdominal hysterectomies I ureter had been divided in 6 , and both ureters in 2 other cases. It has since been computed that in every $10^{23}$ hysterectomies, vaginal and abdoninal, one or both ureters are tied or cut across in at least 3.

From time to time unpublished cases are heard of in which the ureter has been divided partly or entirely; or portions have been unintentionally resected.

For these injuries nephrectomy had hitherto been performed, and in many instances of the kind healthy kidneys have been removed.

This is a discomforting reflection; and, not unnaturally, as soon as accidental surgical wounds became of pretty frequent occurrence there were súrgeons who set themselves to devise some alternative for nephrectomy.

Numerous experiments on animals were made by Tuffier Boari and Pozzi, in France, Gusserow and Pawlik, Alfonso Poggi of Bologna, Van Hook, Byron Robinson, Bovée and others in America, and a great variety of methods have been devised for remedying the injury without acrificing the kidney.

They may be grouped into two distinct classes, namely: (1) Those designed to restore the continuity of the ureter : and, failing this, (2) those for anastomosing the cut end of the ureter with the external surface, with the intestine, or with the bladder.

If the ureter should be wounded during an abdominal or vaginal operation, and the injury is detected by the surgeon at the time, one or the other of these operations ought to be, if possible immediately practised. Such a complication can only be suitably grappled with by one familiar with the varieties and possibilities of surgery which recent experiments and scattered cases have brought to light.

It is very desirable, therefore, that surgeons and gynæcologists who are exposed to the risks of injuring the ureter should have a fair working knowledge of the remedies, short of sacrificing the kidney, which are available.

Uretero-ureteral Anastomosis.-Schopi ${ }^{24}$ in 1886, was the first who practised uretero-ureteral anastomosis in the human subject. After having accidentally divided the ureter near the pelvic brim, when removing an ovarian cyst, he used eight fine silk sutures, passing them through the cellular and muscular tissues only, to nnite the ureter end to end. The patient made an uneventfal recovery from the operation, bu died seven weeks later of tuberculosis. The inference to be drawn from the account of the necropsy is, that there was cicatricial stenosis about the seat of operation.

E. W. Cushing, of Boston, recorded the second case of the end-to-end method, and speaks of his operation as being original, by saying that it forms " a rare, if not unique, incident in the surgery of the ureter." 25 Pawlik, Tuffier, Hochenegg, and $H$. Fritsch, are the other surgeons who have employed the end-to-end method.

In 1887 Alfonso Poggi 26 (of Bologna) suggested the plan (based on experiments on dogs) of invaginating the upper into the lower end of the divided ureter. This is the end-in-end method.

Six years after Poggi's experiments, and seven years later than Schopt's case, Van Hook, ${ }^{27}$ of Chicago, published (in March, 1893) a description of his experiments on dogs, of the lateral implantation of the upper portion of the ureter into an opening in the side of the lower portion. Both Poggi and Van Hook were so impressed by their respective experimental results that they considered a trial of their operations apon man justified.

Weller Van Hook's operation by lateral implantation is performed as follows :-

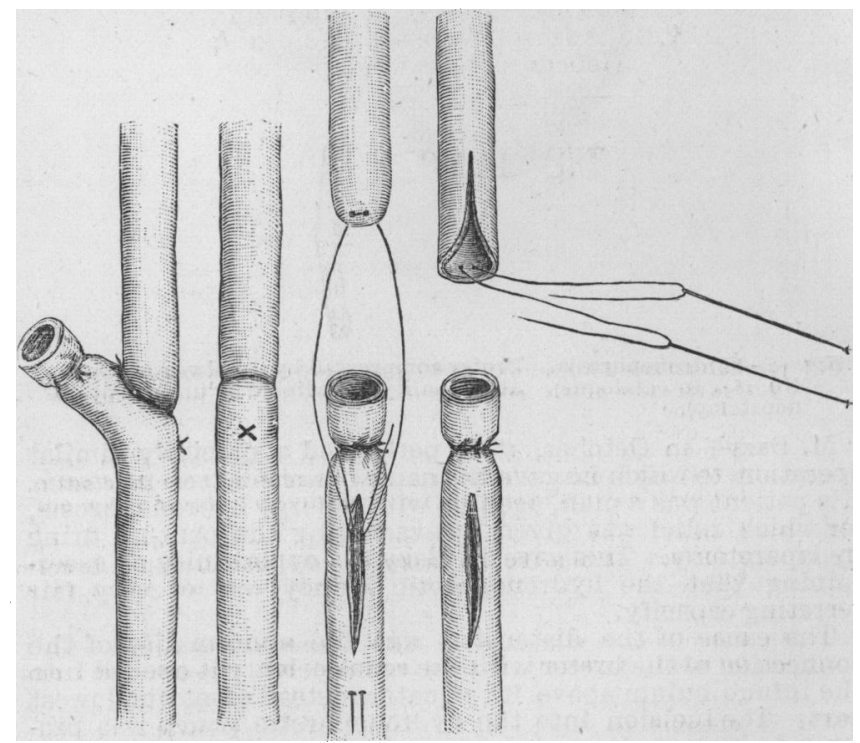

Fig. 12. - Van Hook's method of lateral implantation.

Journal of American Medical A8sociation, vol. xxi, December, 1893.

I. The lower segment is closed by a ligature, one-eighth to a sharp-pointed scissors, a longitudinal incision is made in the wall of this segment of the duct, a quarter of an inch below the ligature. This incision is twice as long as the diameter of the ureter.

2. A longitudinal incision, a quarter of an inch long, is made in the open end of the npper segment. This incision insures the patency of the duct.

3. Two small cambric sewing needles, armed with one thread of sterilised catgut, are passed through the wall of the upper part of the ureter, opposite the slit at the open end, and one-eighth of an inch from the extremity, from within outwards; the needles transfix the wall one-sixteenth of an inch apart, and equidistant from the cut end.

4. The needles are now carried through the slit in the side of the lower segment of the ureter, and made to transfix the wall, side by side, half an inch lower down the tube.

5. By drawing in the two ends of the suture, the upper portion the suture are firmly tied together. As the catgut becomes absorbed in a few days, calculi do not form upon this suture and obstruct the passage of urine.

6 . The ureter at the seat of union is now enveloped carefully with peritoneum. This may be done by lifting the ureter gently into the cavity of the peritoneum, drawing the 
serous membrane carefully behind the ureter, and, after pulling the peritoneum around the ureter, stitching it in position, to permanently enclose and protect the duct. Or the ureter may be surrounded in a completely detached fold of omentum, which is loosely attached by a stitch to the connective tissue about the duct. The omental method is less secure than the other, since the omentum is deprived of its blood supply.

Van Hook points out an important fact in connection with these ureteral operations, namely, "the lumen of the tube can be enormously increased by stretching, without prejudice to the integrity of its walls." Emmet verified this in his operation, where it was of great moment to stretch the lower segment, owing to the great dilatation of the upper.

Howard Kelly of Baltimore, B. Emmet of New York, and Doherty of Georgia, have successfully applied Van Hook's operation to the ureters of women.

When the upper portion of the divided ureter is very much Jistended, and has to be puckered to get it into the lower portion, which may be only half its size, or even less, three sutures, instead of one, might be advantageously employed, as was done by Emmet in the case of the left ureter. ${ }^{28}$ This may be the condition of things if the ureter happens to be cut

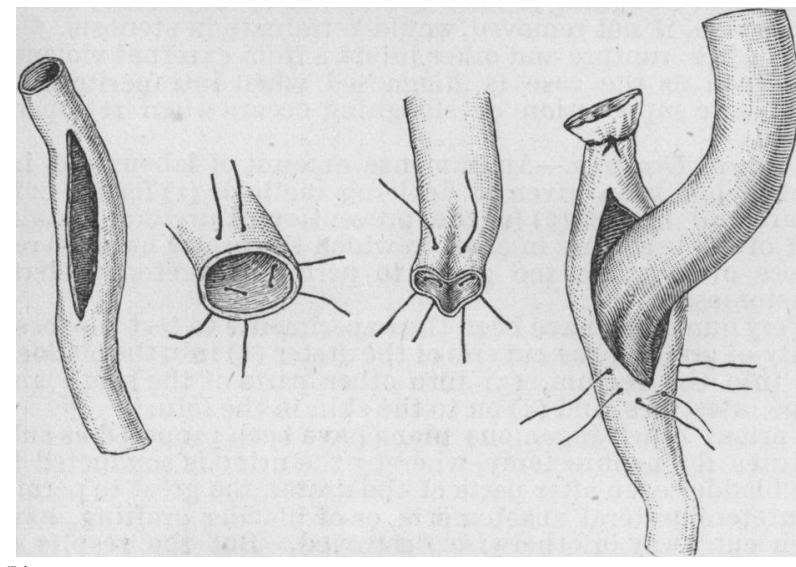

Fig. 13.-Emmet's method of lateral implantation. Bache Emmet, M.D., New York, American Journal of Obstetrics, April, 1895, vol. Mxi.,

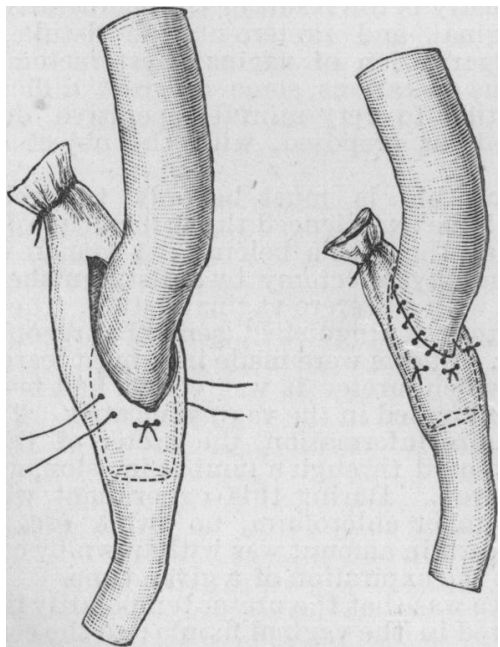

Fig. 14.-Emmet's method of lateral implantation. Bache Emmet, American Journal of Obstetrics, April, 1895 .

just where the pressure of the tumour or adhesions had been exercised. Emmet's abdominal operation was the removal of an cdematous fibroid, attached over the fifth lumbar vertebra, and which had been at one time attached to the uterus.

In Kelly's case, operated upon in May, $1892,{ }^{29}$ as the result of pressure from a nterine myoma, the ureter was enlarged to four times its normal circumference, forming a well-marked hydro-ureter. The operation, therefore, was much easier than it would have been on a normal ureter. Kelly used two sutures instead of one, as Van Hook did; and passed them with a single needle, commencing the passage of the sutures below the slit in the lateral walls of the lower segment of the ureter. Ten fine silk rectangular sutures, catching only the outer coat, then united the edges of the slit to the intussuscepted portion.

Finally Bovée, in 1895, adopted a plan which consists in suturing the cut ends together obliquely. He published an account of it in January, 1897.30 He performed his operation on a woman of 36 , whose right ureter he unintentionally included in a ligature and then divided, when excising the right ovary and tube for an abscess.

He converted the transverse division of the ureter into an oblique one, with some loss of length of the duct. This seemed necessary, as the lower end had been grasped too tightly by stiong forceps, and the upper end by the ligature; thus both ends were damaged.

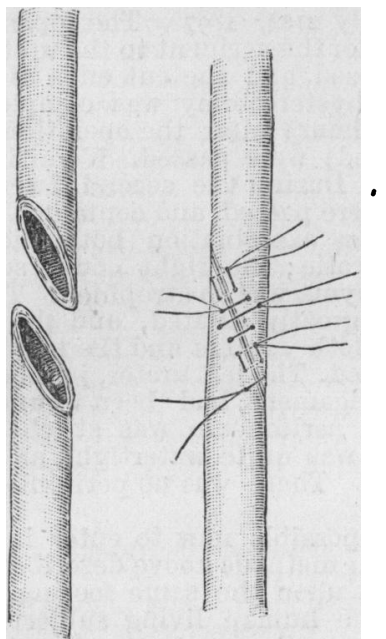

Fig. 15.-Uretero-ureteral anastomosis by the oblique method of Bové J. Wesley Bovée, Annals of Surgery, Part 49.

The cut ends were then dilated for an inch, and approximated with No. I silk, such as is used in intestinal operations; then the ends were joined by rectangular sutures, with two interrupted sutures intervening between each two rectangular sutures. Over these sutures four or five other sutures were inserted, which reached a little further up and down the duct than the rest. The recovery, immediate and remote, was very satisfactory. No sutures penetrated the mucous membrane of the ureter. The peritoneum was carefully sutured over the injured portion of the duct.

Four methods have been employed, as we have now seen, for uniting the cut ends of the ureter:

1. The lateral implantation devised by Van Hook has been successfully performed on three women by different operators in each case. It has led to no contraction or stenosis in experimenting on dogs.

2. The transverse end-to-end union has been practised seven times on the human ureter. Four of these cases have been described as cured. Three died from causes quite unconnected with the ureteral operation, I being from tuberculosis seven weeks afterwards, and the other 2 directly or indirectly from the operation during which the accident to the ureter happened.

3. The oblique end-to-end anastomosis devised by Bovée, and performed by him once and with success.

4. The end-in-end invagination of the upper into the lower portion of the ureter, or the method of Poggi, has been employed at least once successfully on a woman, and Poggi's experiments on dogs were eminently successful.

Budinger's and Tuffier's experiments on dogs of the end-toend and end-in-end methods respectively gave deplorable results. 
F Of the twelve cases of the application of these methods to ureters injured during surgical operations in eleven the section of the duct was complete, and in one incomplete (Pawlik's case):

To this case of incomplete section of the ureter I may add one of my own, in which the dilated ureter was three parts divided. In both of them the mode of treatment was practically the same-namely, closing the wound by very fine silk sutures, passed in the fashion of Lembert, and covering the injured ureter with the peritoneum.

Pawlik's case died of shock fourteen hours after the operation. My patient died fifty-one hours after the operation, but the union was found by Mr. S. Hulke. who made the post-mortem examination, secure, and able to bear the pressure of a stream of water forcibly injected along the ureter from the infundibulum to the bladder. Had this woman lived there is good reason for thinking that stenosis would not have occurred, because of the dilated condition of the ureter.

My patient was a woman 36 years of age, who for eighteen mont hs had been suffering from continual pain and frequent attacks of vomiting caused by a large uterine myoma which was rapidly growing. Complete abdominal hysterectomy was performed on July 21st, 1897 The operation went quite smoothly except for the accident to the ureter, which was immediately recognised, and the cut ends of the ureter were united after the hysterectomy was completed. During the first twenty-four hours after the operation only $7 \frac{1}{2}$ ounces of urine (free of blood) were passed. Vomiting was excessive and continuous. During the second twenty-four hours 27 ounces of urine were passed, and contained no trace of blood. At the post-mortem examination both kidneys were excessively hydronephrotic; the right could scarcely be said to exist, its parenchyma was so atrophied. The calyces of the left kidney were greatly dilated, and the cortical substance was very thin. Both ureters and the renal infundibula were considerably dilated. The left ureter, just beyond its entrance into the broad ligament, had been wounded and closed by sutures, and the peritoneum was stitched over the united ends. The tube was quite watertight, as tested by a strong current of water. There was no peritonitis, and the wound was healing.

It would be impossible now to enter into a minute comparison of the four methods above described. As far as results go all seem to be upon the same footing, for they have all been tested in the human living subject, and from reports published some months or years after the operations no subsequent trouble seems to have occurred to the kidneys.

Personally I may say that if the ureter was completely divided, and was also much dilated, I should adopt Bovée's oblique end-to-end method. If the ureter was completely divided but not dilated, I should prefer Van Hook's. Bovée's might be employed where there is a rather greater loss of substance than could be overcome by Van Hook's method, but the latter would be much more rapidly executed.

For transverse wounds which do not completely divide the ureter, but involve one-third or more of its circumference, Van Hook" has proposed the following operation : "Make two longitudinal incisions in the ureter with a pair of small scissors, beginning at the middle of the wound to be closed these incisions should be equal in combined length to twice the transverse diameter of the tube. Round off the sharp angles of tissues with the scissors and suture longitudinally" (that is, in the direction of the long axis of the tube) "with the object of producing a very wide instead of a very contracted lumen." By this method cicatricial contraction cannot obstruct the flow of urine.

When the wound involves the peritoneal aspect of the duct (as it necessarily does in accidents during abdominal operations) he advises that the union should be protected by surrounding it with a fold of peritoneum.

Fenger thinks that even for incomplete transverse wounds, when intraperitoneal, it will be safer to divide the ureter completely, and then to resort to Van Hook's method of lateral implantation, which, he says, is a tried and successful operation. Emmet is of the same opinion.

A mere puncture, or a small wound which merely gapes slightly, may be securely closed by one or more Lember sutures and a covering of peritoneum. I am of opinion that in many case, where one-third or more of the circumference is involved, the same method will suffice, namely, Lembert sutures and a covering of peritoneum. If it be remembered that in many of the cases in which the ureter is injured during an intraperitoneal operation the tube is more or less dilated, it is not necessary to consider with Van Hook that every incomplete transverse section of the ureter when closed, either by cicatrisation or primary union after direct suture, will have a tendency to result in stenosis.

The case I have alluded to above justifies me in this opinion. If the ureter was divided through half or more of its circumference and dilated, I should do again what I did in this case. If the ureter were not dilated, I should employ one of the methods of Van Hook, being guided by circumstances as to which.

The classes of cases in which uretero-ureteral anastomosis is applicable are the following:

To restore the continuity of the duct (1) after accidental section during abdominal operations.

(2) After unintentional resection of a short length of the duct during abdominal operations. Two or even three inches may be removed, and the ends afterwards brought together without undue tension on the union.

(3) After resection of a portion of the ureter for strictures, vlceration, sloughing around a calculus, or any other condition which, if not removed, would terminate in stenosis.

(4) After rupture and other injuries from external violence - soon as the case is diagnosed when intraperitoneal and before suppuration or sloughing occurs when retroperitoneal.

Ureteral Grafting.-An immense amount of labour and ingenuity has been given to devising methods ( 1 ) for the cure of ureteral fistula, (2) for the prevention of ureteral fistula and of nephrectomy in cases in which the ureter has suffered a loss of substance too great to permit of uretero-ureteral annstomosis.

Very numerous have been the experiments to test the feasibility of grafting the cut end of the ureter (I) into the bladder (2) into the rectum, (3) into other parts of the small and arge intestines, and (4) on to the skin in the loin.

Various other ingenious plans have been proposed as substitutes for nephrectomy, whereby the urine is conducted to the bladder even after parts of the ureter, too great to permit of uretero-ureteral anastomosis, or of bladder grafting, have been cut away or otherwise destroyed. But the results of actual operations show that grafting into the bladderuretéro-cysto-néostomie, as Bazy has named it-should always be the operation of choice when it can possibly be done.

All this industry is the result of the comparative frequency of uretero-vaginal and uretero.uterine fistulæ, especially since the vulgarisation of vaginal hysterectomy. A great many ingenious operations, some of great difficulty and requiring attention to very minute operative details, have been practised, or proposed, with the object of avoiding nephrectomy.

How needinl this is must be only too well known to gurgeons who have experienced the difficulties of identifying to which kidney the fistula belongs: A woman who had undergone vaginal hysterectomy by a distinguished gynæcologist recovered with a uretero-vaginal fistula. The patient was handed over to a distinguished general surgeon to be cured of this fistula. Efforts were made in a most careful manner to ascertain which ureter it was which had been wounded and become entangled in the vaginal cicatrix. These failing to afford definite information, the ureter of the suspected kidney was exposed through a lumbar incision, and was temporarily ligatured. During this experiment, which was of course made under chloroform, no urine escaped by the vagina, but a certain amount was withdrawn by catheter from the bladder at the expiration of a given time.

The inference was that the ureter temporarily ligatured was the one involved in the vaginal fistula; so the corresponding kidney was there and then excised. Imagine the surgeon's chagrin and the patient's distress the next day when it was discovered that though she had lost a healthy kidney the operation had not cured her of the fistula; for the wrong organ had been removed.

It is impossible for me here to describe the work done, or even to name the many workers in this field of experimental and clinical surgery. I can only mention briefly the most 
satisfactory plastic operations upon the ureter for vesical grafting. They may be classified as follows:

1. Invaginating the fistulous aperture itself into the bladder after first incising the vesico-vaginal septum.

2. Grafting the ureter to the bladder through the vagina.

3. Grafting the ureter into the bladder by an extraperitoneal route through an incision in the abdominal wall.

4. Grafting the ureter into the bladder by a transperitoneal or intraperitoneal operation.

Since Simon, in 1869 , first practised nephrectomy as the remedy for urethral fistula, the operation has frequently been performed for this cause up to the present time. Tuffier, in a recently published communication, refers to twenty.four cases which he had collected. But with our present knowledge of the surgery of the ureter, nephrectomy for fistula has become in most instances, I do not say in all, an unjustifiable procedure. It ought to be reserved for quite exceptional cases, as, for instance, where the state of the kidney itself is prejudicial to health, or when the surgeon, having tried and failed, has given up the attempt to cure a troublesome and loathsome fistula by plastic operation.

Nephrectomy as a primary operation for surgical injuries of the ureter is quite unjustifiable; and as a secondary operation for these injuries it comes under the criticism just made upon it for the treatment of fistula.

As a remedy $f \cdot r$ inovable kidney, nephrectomy has come and gone, never, it is hoped, to return.

In cases of limited suppuration, of circumscribed tuberculous disease, of innocent growths, and in certain injuries of the kidney, partial excisions are now being performed in place of nephrectomy.

In many instances of calculous pyonephrosis irrigation of the renal calycee and infundibulum, followed by suture of the kidney, has taken the place of nephrectomy.

In hydronephrosis a few laudable attempts have been made, and in a good proportion of them with success, to remove the cause of the obstruction, and thus by means of a plastic operation to spare the kidney.

In fact, the tendency of the surgery of to-day is to save as much of the kidney tissue as possibly, consistently with the safety and well-being of the patient.

In this very imperfect survey of the origin and progress of renal surgery, I hope I have succeeded in showing that whilst its origin was nephrectomy, its progress, especially during the last ten years, has been in the direction of rendering nephrectomy more and more an operation to he avoided.

15 Archiv REFERENCES.

Ahirurgiviv fir klinische Chirurgie, vol. xliv, 1892, p. 850. 16 C'entralbl. Chirurgie, .894. No 47, p. x145. 17 Deutsche Zeitschr.f. Chirurgie, t. $1 \times 1$ ii p. 309. 18 Acad. de Méd., May 3oth, 1897. 19 Journal of the American Medical Association. Dec. 16th, 1893. p. 9r4. 20 See Edin. Med. Journal, Jan. 1898. 21 Lancet, 1898 , i, p. 18. 22 Med.-Chir. Trans. $188 \mathrm{r}$. 23 Dr. Fred Byron Robinson: Discussion on Fenger's paper. Chicago Medical Reformer March, 1893, p. 200. 24 Centralblatt für Gynüknlogie, No. 30, 1887. 25 An nals of Gynacology and Pediatry, vol. vii, February, 1893. 26 Rif. Med. 1887.88, N.S. vili, 39. 27 Journal of American Medical Association. No. 21 December, 1893. January, 1897 , also September, 1897, p. 318. 31 Op. cit.

\section{: ON PRODUCTION OF SUGAR IN THE LIVER AND ITS UTILISATION IN THE TISSUES " : A REPLY.}

BY F. W. PAVY, M.D., F.R.S., Consulting Physician to Guy's Hospital.

Is an article contained in the British Medical Journar, of February 26th, Dr. Paton has returned to the discussion on the glycogenic theory upon precisely the same lines as in his previous criticisms of my work, which have been fully dealt with by me. May I ask you to accord me space for a reply?

I accede to what is said about the importance of the question of the treatment of diabetes, but I fear that the busy practitioner who may have read the article will nowhere have found in it the proffered help. If I mistake not, indeed, instead of being able to form an "intelligent judgment" his mind will have been left in a mystified state, and yet the object of the article is assistance boldly professed to be $r$ n- dered by a physiologist upon a matter bearing upon treatment. On the contrary, $I$, in my position as a practitioner, have to say that no intelligent judgment to render service in treatment can be framed upon the basis of the glycogenic theory. Can anyone say that he knors anything about diabetes looked at through the glycogenic theory? All that acceptance of the doctrine has done is to lead to serious error in treatment by suggesting to the minds of some that in a system already set wrong by the unnatural presence of sugar within it, matters should be made worse by the administration of carbohydrate, upon the plea that sugar is wanted by the tissues.

To the physiologist, the question of whether the glycogenic theory is right or wrong is not of the same paramount importance that it is to the physician. Whatever may be the view held by the physiologist, in his department Nature goes on working in her own way without being influenced. In the physician's department, on the other hand, an erroneous working is at the foundation of what has to be dealt with, and the essence of the physician's calling is to set the working right. How can this be done upon rational principles without a correct physiological knowledge? In our endeavours to set things right, physiology becomes tested in a manner the opportunity for which is not otherwise afforded, and, viewed in relation to what is learnt from diabetes and its treatment, the glycogenic theory stands in a completely irreconcilable position. If Dr. Paton contends otherwise, let him state his case and deal with the phenomena presented, and show that the glycogenic theory can in reality stand in presence of them. I have stated mine, and have shown that it is not only reconcilable with physiological and medical knowledge, but that it gives us a perfectly intelligible working basis, and a reliable guide in treatment. In the position Dr. Paton has taken, it is due to the medical profession that he should point out the light that the glycogenic theory throws upon the treatment of diabetes.

I cannot think that any useful purpose would be served, even if permission were granted for the occupation of the space required, by following Dr. Paton again in detail as I have done before through the further references upon which his article is based. I have gone through them fully, and the expenditure of time in doing so has prevented my replying earlier to the article.

Dr. Paton relies upon the scattered record that is to be found of the multifarious casual work that is performed. What he has brought forward in this third set of references is of a comparable nature to that examined in my Epicriticism $^{1}$ and Rejoinder. ${ }^{2}$ As I have before stated, there is, perhaps, no subject in physiology in which the experimentalist is beset with so much danger of fallacy as that bearing on the relations of sugar in the animal system, and much, indeed very much, of the work parformed and published fails to stand the test of even quite superticiol examination. I will touch upon what seem to be the most important points in the article before me, at the same time stating that I am ready to meet any other point should it be considered necessary to do so.

Reference is made to numerous and diverse conditions leading to the conversion of glycogen into sugar in the liver and to the production of saccharine urine. The list given might be added to. The result is admittedly an abnormal one, and, I should have thought, is more in consonance with standing as the issue of an abnormal process than as the issue of an exaggeration of a normal function. It is also just what occurs, even to the production of saccharine urine, if the circulation is maintained by artificial respiration in the dead animal. Dr. Paton appears to think differently; but, if he regards diabetes as due to an exaggerated glycogenic function, the onus rests upon him, as I have said, of reconciling the teachings of diabetes with the glycogenic theory.

In view of the position in which things stand, I am surprised at the question of zymin action being brought forward in the article. Dr. Paton has himself carried the discussion of this subject to the Journal of Physiology, where it lies for him to meet the experimental work standing in opposition to him. It may be remembered that in his paper in the Philosophical Transactions on Hepatic Glycogenesis (1894), he contended that the post.mortem oproduction of sugar in the liver is due to a continuance of a vital process instead of to ferment 